\title{
Utilization and Cost of Health Services in Individuals with Traumatic Brain Injury
}

\author{
Clara E. Dismuke ${ }^{1,2,3}$, Rebekah J. Walker ${ }^{1,2}$ \& Leonard E. Egede ${ }^{1,2,3}$ \\ ${ }^{1}$ Health Equity and Rural Outreach Innovation Center (HEROIC), Charleston VA HSR\&D COIN, Ralph H. \\ Johnson VAMC, Charleston, SC \\ ${ }^{2}$ Center for Health Disparities Research, Medical University of South Carolina, Charleston, SC \\ ${ }^{3}$ Division of General Internal Medicine and Geriatrics, Department of Medicine, Medical University of South \\ Carolina, Charleston, SC \\ Correspondence: Leonard E. Egede, MD, MS, Medical University of South Carolina, Center for Health \\ Disparities Research, 135 Rutledge Avenue, Room 280, PO Box 250593, Charleston, SC, 29425, USA. Tel: \\ 1-843-876-1201. E-mail: egedel@musc.edu
}

Received: December 11, 2014 Accepted: February 26, 2015 Online Published: April 15, 2015

doi:10.5539/gjhs.v7n6p156

URL: http://dx.doi.org/10.5539/gjhs.v7n6p156

\begin{abstract}
Traumatic Brain Injury (TBI) has gained attention in the past decade as a "signature injury" in the conflicts in Iraq and Afghanistan. TBI is a major burden for both the military and civilian population in the US and worldwide. It is a leading cause of death and disability in the US and a major health services resource burden. We seek to answer two questions. What is the evidence regarding the association of TBI with health services utilization and costs in the US and worldwide? What is the evidence regarding racial/ethnic, gender, geographic, socio-economic and other disparities in health services utilization and cost in the US and worldwide? To attain this goal we searched several databases using key words to perform a systematic review of the literature since 2000. We found 36 articles to be eligible for inclusion in the review. The evidence demonstrates a wide variation in health services utilization and costs depending on population of study and severity of TBI. The evidence also supports the existence of racial/ethnic, gender, insurance, geographic disparities in the US as well as other unique disparities worldwide.
\end{abstract}

Keywords: traumatic brain injury, utilization, cost, mental health

\section{Introduction}

Traumatic Brain Injury (TBI) has gained attention in the past decade as a "signature injury" in the conflicts in Iraq and Afghanistan (Egede, Dismuke, Echols, 2012). TBI is defined as a physical force to the brain sufficient to cause structural alteration or physiological disruption of brain function that results in altered consciousness, amnesia, change in mental state, neurological deficits, or intracranial lesions. TBI is classified by severity as mild, moderate or severe. Mild TBI is the most common type among veterans who sustain a TBI (Morgan et al., 2012). Approximately 313,816 military service members have been diagnosed with TBI since 2000 (Defense and Veterans Brain Injury Center, 2015). However, TBI is also a major health burden in the US civilian population with approximately 1.7 million TBI injuries annually (Faul et al., 2010). Moreover, TBI is a leading cause of death and disability in the US with approximately 53,000 persons $(18.4$ per 100,000) dying from TBI related injuries annually (Coronado, Xu, Basavaraju et al., 2011). Fire-arms (34.8\%), motor-vehicle accidents (31.4\%) and falls (16.7\%) are the leading causes of TBI related death (4).

TBI is a major health services resource burden with approximately $1,365,000(80.7 \%)$ emergency department (ED) visits and 275,000 (16.3\%) hospitalizations annually (Faul et al., 2010). More recently, evidence has shown that TBI may be accompanied by mental health co-morbidities in the military population, especially PTSD (Taylor et al., 2012). Given the large health and resource burden of TBI, we conducted a systematic review of the literature on health services utilization and costs associated with TBI. We sought to answer the following questions: 1) What is the evidence for TBI associated health services cost and utilization in the US and worldwide? 2) What is the evidence for racial/ethnic, gender, geographic, socio-economic and other disparities in health services cost and utilization in the US and worldwide? We were specifically interested in post-injury cost, 
rather than initial hospitalization cost.

\section{Method}

\subsection{Information Sources, Eligibility Criteria and Search}

In order to answer these two questions, three databases (Medline, PsychInfo, and CINAHL) were searched for articles published between January 2000 through June 2013 using a reproducible strategy. Four searches with broad search terms were performed in each database using MeSH headings search. The first search used the terms traumatic brain injury and cost, the second used traumatic brain injury and utilization, the third used traumatic brain injury and outpatient, and the fourth used traumatic brain injury and ambulatory care.

The following inclusion criteria were used to determine eligible study characteristics: (1) must be published in English, (2) must include health services cost or utilization related to TBI (3) must include adults. Exclusion criteria included: (1) did not focus on clinical efficacy, (2) was not limited to describing cost-effectiveness of an intervention, and (3) did not focus on pediatric TBI.

\subsection{Study Selection and Data Collection}

The process used to screen the citations is shown in Figure 1. Titles were eliminated if they were obviously ineligible, for instance describing cost-effectiveness of an intervention or including children with TBI. Full articles were read and reviewed using a standardized check-list by two independent reviewers (CD, RW). A third independent reviewer (LE) was asked to make the final decision regarding eligibility in the case of disagreement.

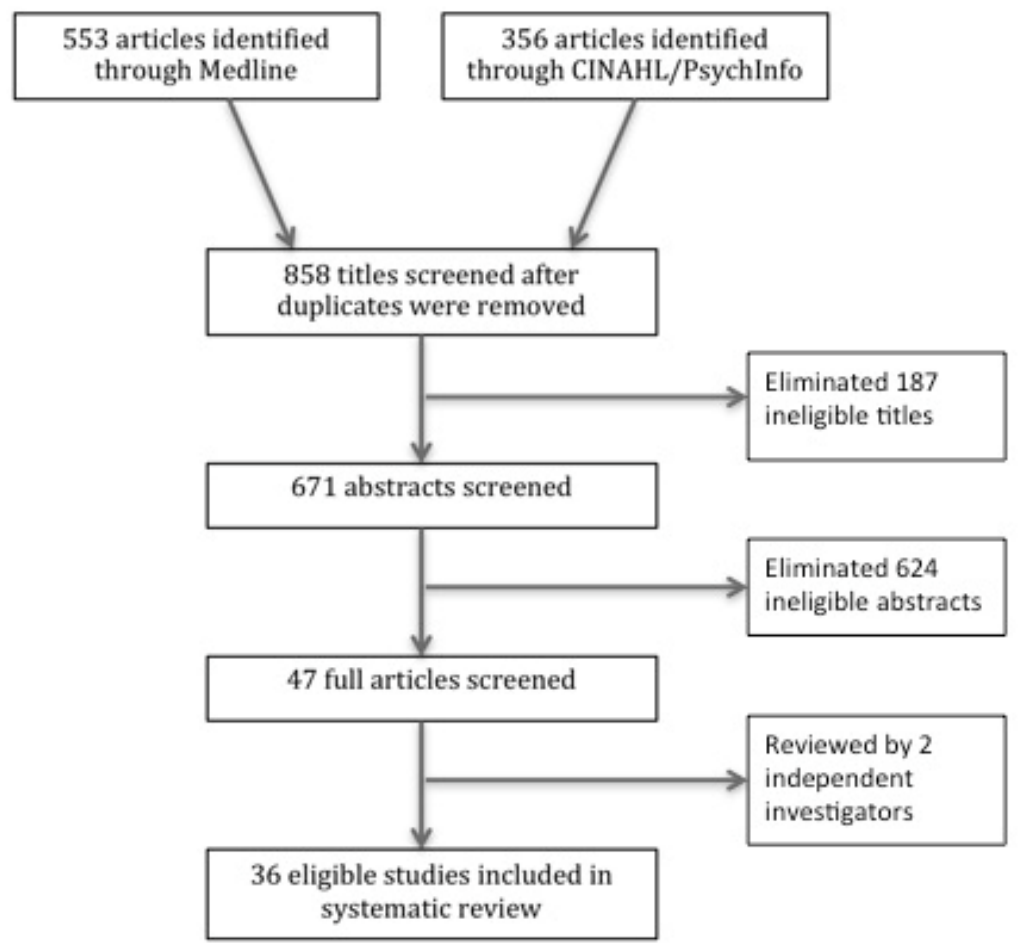

Figure 1. Process for eligible article selection

Data collected from the eligible articles is shown in Tables 1, 2 and 3. A summary of the evidence in each article is presented specific to health services costs (Table 1), health services utilization (Table 2) and disparities in cost and utilization (Table 3). We separated our review and tables by disparities due to our findings of a number of articles encountering racial/ethnic, geographic and other socio-economic disparities in the US and around the world. A narrative review was performed because of the heterogeneous nature of the information, which precluded conducting a meta-analysis.

\section{Results}

\subsection{Study Selection}

Of the 858 articles found through searching three databases, 36 were eligible for inclusion in this 
review. See Table 1 for process details. Fourteen articles provided information on cost of TBI alone (Table 1), seven provided information on utilization in TBI alone (Table 2), four provided information on both cost and utilization (Tables 1 and 2) and eleven provided information on disparities in cost and utilization (Table 3).

\subsection{Cost and Utilization Analysis}

Type of cost and utilization are included in Tables 1 through 3 for each paper reviewed. Cost referred to monetary value either measured in real cost or charges when real cost was not available. Cost included both direct and indirect cost. Monetary value was measured in dollars for the US and the appropriate currency for international studies. Variability in cost can be due to provider differences, third party payer differences, and country differences. For this reason, utilization is a much better standard for comparing resource use, especially between health systems and countries.

Table 1. Cost Studies

\begin{tabular}{|c|c|c|c|}
\hline Study Title & Study Author(s)/Year & Findings & Type of Cost \\
\hline $\begin{array}{l}\text { Prevalence and Costs of } \\
\text { Co-occurring Traumatic } \\
\text { Brain Injury With and } \\
\text { Without Psychiatric } \\
\text { Disturbance and Pain } \\
\text { Among Afghanistan and } \\
\text { Iraq War Veteran VA } \\
\text { Users. }\end{array}$ & Taylor et al., 2012 & $\begin{array}{l}\text { OEF/OIF Veterans with TBI in } 2009 \text { had } 4 \\
\text { times higher median cost relative to those } \\
\text { without TBI. Those with TBI and PTSD } \\
\text { had higher median cost. The median annual } \\
\text { cost per OEF/OIF Veteran diagnosed with } \\
\text { TBI was } \$ 5,831 \text { as compared to } \$ 1,547 \text { for } \\
\text { Veterans without TBI. Among Veterans } \\
\text { with TBI, the median annual cost for those } \\
\text { with TBI, PTSD and pain was } \$ 7,974 \text {. }\end{array}$ & $\begin{array}{l}\text { Total VA health } \\
\text { services costs for } \\
\text { OEF/OIF Veterans } \\
\text { with TBI, with and } \\
\text { without comorbid } \\
\text { PTSD. }\end{array}$ \\
\hline $\begin{array}{l}\text { Non-surgical Intervention } \\
\text { and Cost for Mild } \\
\text { Traumatic Brain Injury: } \\
\text { Results of the WHO } \\
\text { Collaborating Centre } \\
\text { Task Force on Mild } \\
\text { Traumatic Brain Injury }\end{array}$ & Borg et al., 2004 & $\begin{array}{l}\text { Review article of non-surgical intervention } \\
\text { and mild TBI costs. Found indirect costs } \\
\text { are much higher than direct medical costs. } \\
\text { Admission and radiological policies are } \\
\text { determining factors of direct costs. }\end{array}$ & $\begin{array}{l}\text { Direct and Indirect } \\
\text { Costs For Mild TBI. }\end{array}$ \\
\hline $\begin{array}{l}\text { Trend and Geographic } \\
\text { Analysis for Traumatic } \\
\text { Brain Injury Mortality } \\
\text { and Cost Based on } \\
\text { Market Scan Database }\end{array}$ & Hu et al., 2013 & $\begin{array}{l}\text { For } 52,721 \text { privately insured and } 23,592 \\
\text { Medicare insured patients with TBI from } \\
2004 \text { to } 2009 \text {, median hospital costs for } \\
\text { adults were } \$ 13,000 \text { for } 18-64 \text { and } \$ 9,000 \\
\text { for } 65+\text {. Significant differences in cost by } \\
\text { geographic region were also found with } \\
\text { the highest costs in California and } \\
\text { Washington. }\end{array}$ & $\begin{array}{l}\text { Privately insured and } \\
\text { Medicare inpatient } \\
\text { hospital costs. }\end{array}$ \\
\hline $\begin{array}{l}\text { Utilization and Costs of } \\
\text { Health Care after } \\
\text { Geriatric Traumatic Brain } \\
\text { Injury }\end{array}$ & Thompson et al., 2012 & $\begin{array}{l}\text { Among adults aged } 55-84 \text { years old in the } \\
\text { National Study on the Costs and Outcomes } \\
\text { (NSCOT) database diagnosed with TBI, } \\
\text { unadjusted mean costs ranged from } \\
\$ 72,733 \text { in the } 75-84 \text { group to } \$ 77,872 \text { in } \\
\text { the } 55-64 \text { group. In adjusted cost model, } \\
\text { index hospitalization and inpatient } \\
\text { rehabilitation costs were lowest among } \\
75-84 \text { while outpatient care and nursing } \\
\text { home costs were lowest among younger } \\
\text { ages. }\end{array}$ & $\begin{array}{l}\text { Index hospitalization, } \\
\text { inpatient, outpatient } \\
\text { and nursing home } \\
\text { costs for geriatric TBI. }\end{array}$ \\
\hline $\begin{array}{l}\text { The Direct Economic } \\
\text { Burden of Blunt and } \\
\text { Penetrating Trauma in a } \\
\text { Managed Care } \\
\text { Population }\end{array}$ & Davis KL et al., 2007 & $\begin{array}{l}\text { Initial hospitalization charges ranged from } \\
\$ 32,627 \text { for TBI alone to } \$ 103,667 \text { for TBI } \\
\text { along with other trauma. Initial } \\
\text { hospitalization charges were highest for } \\
\text { those admitted to Level } 1 \text { trauma centers }\end{array}$ & $\begin{array}{l}\text { Initial hospitalization } \\
\text { charges for TBI with } \\
\text { and without other } \\
\text { trauma. }\end{array}$ \\
\hline
\end{tabular}


Mental Illness, Traumatic

Brain Injury, and

Medicaid Expenditures

Outcomes and costs of acute treatment of traumatic brain injury

Charges and lengths of stay for acute and inpatient rehabilitation treatment of traumatic brain injury 1990-1996

The Costs of Traumatic Brain Injury

\section{Health Care Costs}

Associated with Traumatic Brain Injury and Psychiatric Illness in Adults

Medical Care Costs Associated with Traumatic Brain Injury over the Full Spectrum of Disease: A Controlled Population-Based Study
Wei et al., 2005

Wei et al. 2005

McGarry L et al., 2002

Kreutzer et al., 2001

Thompson K 2001

Rockhill et al., 2011

Leibson et al., 2012 except for TBI with other trauma while charges were highest for nontrauma centers.

Among a Medicaid population in four states, the presence of comorbid mental illness increased the cost of care for those with TBI. For those without severe mental illness (SMI) and TBI, total expenditures were $\$ 6,093$ compared to $\$ 8,723$ for those with TBI and an SMI in Alabama, $\$ \$ 6,919$ vs. $\$ 13,688$ for Georgia, $\$ 21,924$ vs. $\$ 10,907$ for New Jersey, and $\$ 7,154$ vs. $\$ 19,986$ for Wisconsin.

For patients aged 16 and older hospitalized for TBI between $1 / 1 / 97$ and 6/20/1999, costs of hospitalization ranged from an average of $\$ 8,189$ for moderate to $\$ 33,537$ for critical TBI. Costs ranged from $\$ 15,860$ for falls to $\$ 20,084$ for gunshot wounds and 20,522 for motor vehicle accidents.

Over a 7 year period between 1990-1996, acute care daily charges showed almost routine increases while lengths of stay generally showed a downward trend with annual reductions averaging 2.25 days. The rise in rehabilitation charges was offset by corresponding decreases in lengths of stay. Increases in daily charges for rehabilitation were comparable to general medical care prices while rate of change in acute care charges was substantially greater, about $10 \%$ higher than medical care prices.

Mean cost of treating a TBI at TBI Model System facilities were about $\$ 98,612$ per case while the mean costs of inpatient rehabilitation were $\$ 43,212$, not including physician charges.

Average costs were $76 \%$ higher in the 3 years after injury for the mild TBI group and 5.75 times greater for moderate to severe TBI group when compared to controls. Presence of psychiatric illness associated with more than doubling of total costs for both inpatient and outpatient non-mental health care.

For incident TBI in the Rochester Epidemiology Project (REP) among residents of Olmsted Minnesota, most incremental costs occurred within the first 6 months while significant long-term incremental costs were not apparent among 1 year survivors. Cost differences between possible TBI cases and matched controls were not as great in the first 6 months, but were substantial among 1 year survivors.
Medicaid cost for TBI with and without comorbid mental illness.

TBI inpatient hospital cost for moderate and critical TBI.

Length of stay utilization and charges for inpatient hospital and inpatient rehabilaition for TBI.

Inpatient hospitalization and inpatient rehabilaition cost at TBI Model System Rehabiliation facilities for TBI.

Inpatient and outpatient costs of TBI with and without comorbid psychiatric conditions.

Short and long-term incremental costs for 1 year survivors of TBI. 


Health and Economic
Burden of Traumatic
Brain Injury: Missouri,
2001-2005
The contribution of
traumatic brain injury to
the medical and
economic outcomes of
motor vehicle-related
injuries in Ohio
Long-Term Medical Care
Utilization and Costs
Among Traumatic Brain
Injury Survivors

Characteristics of acute treatment costs of traumatic brain injury in Eastern China-a mulit-centre prospective observational study

The economic cost of brain disorders in Europe

Determinants of hospital costs associated with traumatic brain injury in England and Wales

\section{Kayani et al., 2009}

Vangel SJ et al., 2005

Rochette LM et al., 2009

Vangel SJ et al.

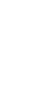

Olesen et al., 2012

Yuan et al., 2012

Morris S et al., 2008

During 2001-2005, mean cost per
hospitalization and ED visit was
approximately $\$ 6,948$.

Among injured roadway users in Ohio between 2003 and 2006, when compared with a non-TBI injury, total hospital charges increased by a factor of 1.35 for a TBI. Mean hospital charges were $\$ 46,441$ for a TBI roadway injury versus $\$ 32,614$ for a non-TBI roadway injury.

Among 63 participants in Michigan, residential, home health and state case management billings accounted for $15 \%$ of total billing, nearly half of total charges and $27 \%$ of Medicaid payments. Medications accounted for $39 \%$ of total billings, $19 \%$ of Medicaid payments and 7\% of charges. Outpatient services (excluding primary care program services) contributed $21 \%$ of total billings, $24 \%$ of total charges and $31 \%$ of Medicaid payments. Primary care accounted for $13 \%$ of billings, $4 \%$ of charges and $6 \%$ of Medicaid payments. Emergency room visits contributed $12 \%$ of billings, $8 \%$ of charges and $7 \%$ of Medicaid payments. Motor deficits (FIM score) at discharge from inpatient rehabilitation showed inverse relationship to billings Hospitalization costs were highest for traffic accidents and lowers for blows to the head. In adjusted analysis, lower Glasgow coma score, longer LOS, male sex, transient patient status. Traffic accident, injury occurring on a construction site, treatment at a tertiary hospital, neurosurgical ICU, ICU stay, polytrauma and those needing neurosurgery had significantly higher costs while good recovery and self-paying patients had lower costs. A double LOS was associated with a 1.6 times higher hospital cost.

The latest estimate for the cost of TBI in Europe in 2010 was $€ 2,697$ in direct health care costs.

Mean costs per patient were highest in those with an Abbreviated Injury Scale (AIS) of 5. Length of stay in critical care accounted for $51 \%$ of mean total costs, regular ward $38 \%$ and travel costs $5 \%$. Those aged 45-64 years had highest costs. Costs were highest among those injured in motor vehicle accidents, those with a lower Glascow coma score (GCS) and those with a higher AIS. Co-existing neck, thorax, abdomen and spine also increased costs.

\author{
Inpatient \\ hospitalization and \\ emergency department \\ costs for TBI. \\ Inpatient hospital \\ charges for TBI and \\ non-TBI roadway \\ injuries.
}

\section{Long-term care costs} for TBI.
Direct costs of TBI in Europe.

Inpatient hospital costs of TBI in England and Wales. 
Surgery was associated with higher costs as was being seen in a hospital with a neurosurgical unit, being seen by a specialist from anesthesia, orthopedics, and general surgery. Mortality was associated with lower costs.

Economic evidence in Berg J., 2004 trauma: a review
Based on 2004 data, average inpatient cost for TBI in Germany was $€ 2,529$, compared with $€ 2,833$ in Spain and $€ 3,024$ in Sweden. Average inpatient cost for concussion was $€ 1,071$ for Germany, $€ 987$ for Spain, and €927 for Sweden. Average inpatient cost for severe brain injury was $€ 6,647$ for Germany, $€ 6,362$ for Spain and $€ 6,045$ for Sweden.

Table 2. Utilization Studies

\begin{tabular}{ll}
\hline Study Title & Study Author(s)/Y \\
\hline Traumatic Brain Injury & Faul et al., 2010 \\
in the United States: & \\
Emergency Department & \\
Visits, Hospitalizations & \\
and Deaths, 2002-2006 & \\
Pharmacotherapy & Morgan et al., 201 \\
Regimens Among & \\
Patients with & \\
Posttraumatic Stress & \\
Disorder and Mild & \\
Traumatic Brain Injury. &
\end{tabular}

Outcomes and Costs of Acute Treatment of Traumatic Brain Injury
McGarry et al., 2002

Rochette LM et al., 2009

The contribution of traumatic brain injury to the medical and economic outcomes of motor vehicle-related injuries in Ohio Long-Term Medical Care Utilization and Costs Among Traumatic Brain Injury Survivors

Economic evidence in trauma: a review

Vangel SJ et al., 2005

Findings

TBI injuries were associated with 275,000 hospitalizations and 1,365 million ED visits in the US.

In a study of OEF/OIF Veterans with co-morbid TBI and PTSD compared with with PTSD alone, the patients with PTSD and TBI were more likely to be prescribed an antidepressant a sedative-hypnotic, or an antipsychotic. The patients with TBI were also significantly more likely to receive psychotropic polypharmacy and to receive higher doses of psychiatric medications.

More than $4 / 5$ of study subjects received CAT scan while MRI and electroencephalography were used less frequently. Use of all diagnostic tests increased with Abbreviated Injury Scale (AIS) score. Surgery and mean days on vent increased with AIS. 1/5 with critical TBI received ventriculostomy Most frequently used medicines were analgesics and anxiolytics as well as anticonvulsants in more severe injuries. $1 / 3$ were on mechanical ventilation and $2 / 3$ received ICU care.

Among injured roadway users in Ohio between 2003 and 2006, when compared with a non-TBI roadway injury, the odds of requiring a ventilator $(\mathrm{OR}=3.66)$ and being admitted to the ICU (OR=2.51) were significantly higher for a TBI roadway injury. Most frequent prescriptions filled were anticonvulsant/mood stabilizers.
Type of Utilization

Inpatient hospital and emergency department utilization in TBI.

Pharmaceutical utilization in OEF/OIF Veterans with TBI and comorbid PTSD and PTSD alone.

Imaging, surgery, ICU and ventilator utilization in TBI.

Ventilator and ICU utilization for roadway injuries with and without TBI.

Prescription utilization in TBI.
CT utilization in Spain is much lower than Sweden and German with only $6 \%$ use.
CT utilization in Spain, Sweden and 


\section{Emergency \\ department \\ management of mild \\ traumatic brain injury \\ in the USA}

\section{Service Utilization \\ following Traumatic \\ Brain Injury}

\section{A multi-Center \\ Analysis of \\ Rehospitalizations Five}

Years after Brain Injury

Underutilization of neuropscychology in traumatic brain injury rehabilitation: Is managed care to blame?

Severity of injury and Service Utilization Following Traumatic Brain Injury The First 3 Months

Rehabilitation of traumatic brain injury in Italy: a multi-center study.
Bazarian et al., 2005

Of the patients with isolated mild TBI, $44.3 \%$ underwent computed tomography, 23.9\% underwent other non-extremity, non-chest $\mathrm{x}$ rays, $17.1 \%$ received wound care and $14.1 \%$ received intravenous fluids. However, only $43.8 \%$ had an assessment of pain. Of those with documented pain, only $45.5 \%$ received analgesics in the ED. Nearly $38 \%$ were discharged without recommendations for specific follow up.

Hodgkinson et al., 2000

$81 \%$ of sample used medical and allied health services and $66 \%$ used transport, and $40 \%$ used vocational rehabilitation services.

Marwitz JH, et al., 2001

Schatz et al., 2001

Philips VL et al., 2004

Zampolini et al., 2011
Rehospitalization rates among a sample of patients with TBI declined between the one and five year follow up period from $23 \%$ to $17 \%$. During the first year orthopedic and reconstructive surgery $(25 \%)$ were the primary reason, dropping to $13 \%$ in year 5 . Infections accounted for $10 \%$ of readmissions at 1 year follow-up and $8 \%$ at 5 years after injury. Pneumonia was the most frequent infection $(44 \%)$ at 1 year and 5 years $(43 \%)$. Incidence of rehospitalizations relating to seizures ad psychiatric disorders were $12 \%$ at one year and rose to $19 \%$ at 5 years.

Only $26 \%$ of 273 patients with TBI received a neuropsychology evaluation (NPE). They were younger, more likely to be involved in liability claims, achieved a higher functional ability in primary rehabilitation and attended multiple rehabilitation facilities.

Among 113 individuals treated in Georgia TBI Model Systems, during first 3 months post rehabilitation discharges, at least $80 \%$ saw an $\mathrm{MD}, 42 \%$ reported 4 or more MD visits, more than $50 \%$ attended day rehabilitation programs, $42 \%$ had physical therapy, 36\% occupational therapy, and $33 \%$ speech pathology. $11 \%$ psychological counseling. Mean LOS was $87.31,40.4 \%$ of patients had access to rehabilitation facilities after a month.
Germany.

Imaging, wound care, IV and pharmaceutical utilization in mild TBI.

Medical, allied health, transportation and vocational rehabilitation utilization in TBI.

Rehospitalizations in TBI.

Neuropsychology evaluation utilization in TBI.

Physician, rehabilaition and mental health utilization in TBI.

Length of stay and rehabilaition utilization in TBI in Italy. 
Table 3. Disparities Studies

\begin{tabular}{|c|c|c|c|}
\hline Study Title & Study Author(s)/Year & Findings & $\begin{array}{l}\text { Type of } \\
\text { Utilization/Cost }\end{array}$ \\
\hline $\begin{array}{l}\text { Impact of socioethnic } \\
\text { factors on outcomes } \\
\text { following traumatic } \\
\text { brain injury. }\end{array}$ & Heffernan et al., 2011 & $\begin{array}{l}\text { In a Level } 1 \text { trauma ED population, private } \\
\text { insurance associated with shorter length of } \\
\text { stay and intoxication with longer length of } \\
\text { stay. Non-Caucasian race and lack of } \\
\text { insurance associated with lower likelihood of } \\
\text { placement in rehabilitation. }\end{array}$ & $\begin{array}{l}\text { Length of stay, } \\
\text { emergency } \\
\text { department and } \\
\text { rehabilaition } \\
\text { utilization in TBI. }\end{array}$ \\
\hline $\begin{array}{l}\text { The effect of insurance } \\
\text { status, race, and gender } \\
\text { on ED disposition of } \\
\text { persons with traumatic } \\
\text { brain injury. }\end{array}$ & Selassie et al., 2004 & $\begin{array}{l}\text { In a state of SC hospital ED population, after } \\
\text { adjusting for demographic, clinical and } \\
\text { hospital characteristics, uninsured and black } \\
\text { females had lower likelihood of } \\
\text { hospitalization }\end{array}$ & $\begin{array}{l}\text { Emergency } \\
\text { department and } \\
\text { hospitalization } \\
\text { utilization in TBI. }\end{array}$ \\
\hline $\begin{array}{l}\text { Ethnic and racial } \\
\text { disparities in emergency } \\
\text { department care for } \\
\text { mild traumatic brain } \\
\text { injury }\end{array}$ & Bazarian, et al., 2003 & $\begin{array}{l}\text { In a national sample of ED visits, after } \\
\text { controlling for confounders, Hispanics more } \\
\text { likely to receive nasogastric tube, nonwhites } \\
\text { more likely to receive care by a resident and } \\
\text { less likely to be sent back to a referring } \\
\text { physician after ED discharge }\end{array}$ & $\begin{array}{l}\text { Nasogastric tube } \\
\text { and physician } \\
\text { utilization in TBI. }\end{array}$ \\
\hline $\begin{array}{l}\text { Does Health Care } \\
\text { Insurance Affect } \\
\text { Outcomes After } \\
\text { Traumatic Brain Injury? }\end{array}$ & Alban et al., 2010 & $\begin{array}{l}\text { Insured patients had longer ICU stay in } \\
\text { unadjusted analysis. }\end{array}$ & $\begin{array}{l}\text { ICU utilization in } \\
\text { TBI. }\end{array}$ \\
\hline $\begin{array}{l}\text { Traumatic Brain Injury } \\
\text { Hospitalizations Among } \\
\text { American } \\
\text { Indians/Alaska Natives }\end{array}$ & $\begin{array}{l}\text { Rutland-Brown W. et al., } \\
2005\end{array}$ & $\begin{array}{l}\text { Among } 182,130 \text { individuals hospitalized with } \\
\text { TBI in } 13 \text { states, American Indians and } \\
\text { Alaskan Natives (AI/AN) had the highest age } \\
\text { adjusted rates of hospitalization for TBI } \\
\text { relative to other race/ethnicities. The greatest } \\
\text { difference occurred for individuals between } \\
20 \text { and } 44 \text { years old. High blood alcohol levels } \\
\text { and low use of vehicle restraints were more } \\
\text { prevalent in AI/AN. }\end{array}$ & $\begin{array}{l}\text { Hospital utilization } \\
\text { in TBI. }\end{array}$ \\
\hline $\begin{array}{l}\text { Measuring Unmet } \\
\text { Needs and Services } \\
\text { Among Persons with } \\
\text { Traumatic Brain Injury }\end{array}$ & Heinemann et al., 2002 & $\begin{array}{l}\text { Most prevalent unmet needs were for memory } \\
(50.5 \%) \text { job skills }(46.3 \%) \text {, increasing income } \\
(50.5 \%) \text {. Black, younger and single } \\
\text { individuals as well as those dependent in one } \\
\text { or more daily activities and with more recent } \\
\text { injuries had greater unmet needs. }\end{array}$ & $\begin{array}{l}\text { Unmet Needs in } \\
\text { TBI }\end{array}$ \\
\hline $\begin{array}{l}\text { The Use of Medicaid } \\
\text { Waivers and their } \\
\text { Impact on Services }\end{array}$ & Spearman RC et al., 2001 & $\begin{array}{l}\text { A review of TBI Medicaid Waivers in six } \\
\text { states allowing flexibility in care and design } \\
\text { of integrated service plans for those with TBI } \\
\text { showed that the ability to obtain a waiver was } \\
\text { associated with social-medical-political } \\
\text { climate, similarity to other waivers, ability to } \\
\text { strengthen access and reduce barriers, and } \\
\text { expenditure of resources. Managing waivers } \\
\text { was associated with cost effectiveness, } \\
\text { developmental process of waiver } \\
\text { implementation, ability to improve access and } \\
\text { reduce barriers, and expenditure of resources. }\end{array}$ & $\begin{array}{l}\text { Medicaid Waiver } \\
\text { Utilization in TBI. }\end{array}$ \\
\hline $\begin{array}{l}\text { National estimates of } \\
\text { hospitalization charges }\end{array}$ & $\begin{array}{l}\text { Schootman M. et al., } \\
2003\end{array}$ & $\begin{array}{l}\text { Mean and median acute care charges were } \\
\text { only slightly higher for males compared with }\end{array}$ & $\begin{array}{l}\text { Inpatient hospital } \\
\text { charges in TBI. }\end{array}$ \\
\hline
\end{tabular}


for the acute care of traumatic brain injuries

females however the median age increased with age until age 34 after which it remained stable. Mean and median charge increased with increasing injury severity. Mean and median charges were highest for the western region of the US and for persons covered by Medicaid and those treated at urban teaching hospitals.

Is There Equity in Long-Term Healthcare Utilization After Traumatic Brain Injury?

Sixteen years on: Has quality of care for rural and non-compensable traumatic brain injury clients improved

Rehabilitation Outcomes of Terror Victims with Multiple Traumas
Willemse-van Son MA 2009

O'Callaghan et al., 2009

Schwartz et al., 2008
Among 79 patients with moderate/severe TBI in Netherlands, those with a high locus of control with the physician were more likely to visit medical specialists and use supportive care than those with lower levels of internal locus of control.

Rural TBI patients more likely to be treated in non-inpatient setting than urban TBI patients in Australia though no significant difference in functional outcome.

Terror victims with TBI had higher rates of brain surgery but no difference in length of stay in hospital relative to non-terror victims in Israel.
Physician and supportive care utilization in TBI in Netherlands.

Non-inpatient utilization in TBI in Australia.

Surgical utilization in TBI in Israel.

\section{Discussion}

\subsection{Health Services Cost Associated With TBI in the United States}

Costs associated with TBI vary widely depending on the population studied, severity of injury and time period. In an early review of mild TBI without surgical intervention, indirect costs were much higher than direct costs, accounting for $92 \%$ of total costs in 1981 dollars (Borg et al., 2004). Admission and radiologic policies were found to be determining factors in the level of direct costs (Borg et al., 2007). A study conducted between 1997 and 1999 found that costs of hospitalization ranged from an average of $\$ 8,189$ for moderate to $\$ 33,537$ for critical TBI (McGarry et al., 2002). Those due to falls averaged $\$ 15,860$, while those due to gunshot wounds averaged \$20,084 and motor vehicle accidents averaged \$20,522 (McGarry et al., 2002). In a study from 1990-1996, acute care daily charges showed routine increases, while lengths of stay generally decreased. (Kreutzer et al., 2001) Rehabilitation charges were about $10 \%$ higher than medical care prices, and offset the corresponding decreases in lengths of stay. (Kreutzer et al., 2001)

Since 2000, there have been a number of studies in the US and world wide of health services costs associated with TBI in various populations with costs ranging from $\$ 9,000$ to $\$ 103,667$. (Borg et al., 2004; Hu et al., 2013; Thompson et al., 2012; Davis et al., 2007; Wei et al., 2005; McGarry et al., 2002; Kreutzer et al., 2001; Thompson, 2001; Rockhill et al., 2011; Leibson et al., 2012; Kayani et al., 2009; Rochette et al., 2009; Vangel et al., 2005). Most recent, a study from 2004 to 2009 found that median hospital costs for adults were $\$ 13,000$ for the 18-64 age group and \$9,000 for the 65 and older age group. (Hu et al., 2013) In a 2005 study, unadjusted total mean one year costs were $\$ 77,872$ for those aged 55-64 years, $\$ 76,903$ for those aged $65-74$ years and $\$ 72,733$ for those aged 75-84 years in 2005 dollars (Thompson et al., 2012). In a study of the managed care population, initial hospitalization charges ranged from $\$ 32,627$ for TBI alone to $\$ 103,667$ for TBI along with other trauma (Davis et al., 2007). Another study found mean cost of treating a TBI to be $\$ 96,612$, with inpatient rehabilitation accounting for on average \$43,212, not including physician charges (Thompson, 2001).

Costs are known to vary due to severity. One case controlled found total health services ranged from $\$ 12,990$ for mild TBI vs. \$42,4441 for moderate/severe in 2009 dollars (Rockhill et al., 2011). As a comparison, total health services costs for non-TBI matched controls were $\$ 7,377$ (Rockhill et al., 2011). Mean costs were $76 \%$ higher in the three years after injury for the mild TBI group and 5.75 times greater for the moderate/severe group compared to controls (Rockhill et al., 2011). Another case control study for that for definite and probable TBI, most incremental costs occurred within the first six months while significant long-term incremental medical 
costs were not apparent among one-year survivors (Leibson et al., 2012). Cost differences between possible TBI cases and matched controls were not as great in the first 6 months but were substantial among one-year survivors (Leibson et al., 2012).

Studies also found significant variation in cost by geographic region, type of service, and comorbidity. One study found the highest costs occurring in the states of California and Washington (Hu et al., 2013). State specific studies found varying costs but often categorized costs differently, making comparisons difficult (Kayani et al., 2009; Rochette et al., 2009; Vangel et al., 2005). A study specific to the geriatric population found hospitalization and inpatient rehabilitation costs significantly lower in the 75-84 age category while outpatient care costs and nursing home costs were lower in the younger age categories (Thompson et al., 2012). In a study of the Medicaid population in four states, the presence of co-morbid mental illness increased the cost of care for those with TBI (Wei et al., 2005). Total expenditures ranged by state from $\$ 6,093$ to $\$ 10,907$ for those without SMI, compared to $\$ 8,723$ to $\$ 21,924$ for those with SMI (Wei et al., 2005). Another study showed presence of psychiatric illness was associated with more than doubling of total costs for both inpatient and outpatient non-mental health care (Rockhill et al., 2011).

Finally, a national study of US Operation Enduring Freedom/Operation Iraqi Freedom (OEF/OIF) veterans treated in the VA found that OEF/OIF veterans with TBI had 4 times higher median health services costs relative to OEF/OIF veterans without TBI (\$5,831 vs. $\$ 1,547)$ (Taylor et al., 2012). Mental health co-morbidities in the military population increase health services costs associated with TBI, similarly to civilian populations, with those with TBI and PTSD having a median cost of $\$ 5,053$ relative to those with TBI alone being $\$ 2,391$ (Taylor et al., 2012).

\subsection{International Health Services Costs Associated With TBI}

Health services costs associated with TBI have also been estimated for other countries. In China, hospitalization costs were found to be highest for traffic accidents and lowest for blows to the head (Yuan et al., 2012). Multiple factors were associated with higher acute hospitalization costs with doubling of length of stay associated with a $61 \%$ higher hospital cost (Yuan et al., 2012). The latest estimate for the cost of TBI in Europe, based on data from 30 European countries in 2010 was $€ 2,697$ in direct health care costs (Olsen et al., 2012). A study of England and Wales found that length of stay in critical care accounted for $51 \%$ of mean total costs, regular ward $38 \%$ and travel costs 5\%. (Morris et al., 2008) Those aged 45-64 years had the highest costs. (Morris et al., 2008) In another European study based on 2004 data, average inpatient cost for TBI in Germany was $€ 2,529$, compared with $€ 2,833$ in Spain and $€ 3,024$ in Sweden. Average inpatient cost for concussion was $€ 1,071$ for Germany, $€ 987$ for Spain, and $€ 927$ for Sweden. Average inpatient cost for severe brain injury was $€ 6,647$ for Germany, $€ 6,362$ for Spain and $€ 6,045$ for Sweden (Berg, 2004).

\subsection{Health Services Utilization Associated With TBI in the United States}

TBI injuries are associated with approximately 275,000 hospitalizations and 1,365 million ED visits in the US annually (Faul, 2010). One study found that $81 \%$ used medical and allied health services, $66 \%$ used transport and $40 \%$ used vocational rehabilitation (Hodgkinson et al., 2000). In Georgia, during the first three months of post rehabilitation discharges, at least $80 \%$ saw an MD, $42 \%$ reported four or more MD visits, over $50 \%$ attended day rehabilitation programs, $42 \%$ had physical therapy, $36 \%$ occupational therapy, $33 \%$ speech pathology, and $11 \%$ had psychological counseling. (Philips et al., 2004) Re-hospitalization rates declined between the one and five year follow up period from $23 \%$ to $17 \%$ (Marwitz et al., 2001). While during the first year, orthopedic and reconstructive surgery were the primary reason (25\%), infections accounted for $10 \%$ of readmissions at 1 year follow-up and $8 \%$ at 5 years after injury (Philips et al., 2004). Incidence of rehospitalizations relating to seizures ad psychiatric disorders were $12 \%$ at one year and rose to $19 \%$ at 5 years (Philips et al., 2004).

Financial incentives may influence end of life care for severe TBI (Holloway et al., 2010). Hospitals have been found to have a strong incentive and insurers a strong disincentive to pay for performing tracheotomies since doing so quintuples a hospital's DRG associated reimbursement rate (Holloway et al., 2010). If a tracheotomy is not performed, the hospital has a financial incentive to discontinue aggressive treatment due to the lower fixed DRG reimbursement rate (Holloway et al., 2010). In another sample of 273 patients with TBI, only $26 \%$ were found to have received a neuropsychology evaluation. (NPE) (Schatz et al., 2001). These patients were younger, more likely to be involved in liability claims, achieved a higher functional rehabilitation and attended multiple rehabilitation facilities (Schatz et al., 2001).

A number of patient characteristics are significantly associated with utilization of various services. In a national study of the ED population diagnosed with isolated mild TBI, $44.3 \%$ were found to have received CT, $23.9 \%$ other non-extremity, non-chest x-rays, $17.1 \%$ wound care and 14.1\% IV fluids (Bazarian et al., 2005). However, 
only $43.8 \%$ of the ED population were assessed for pain and of those with documented pain, only $45.5 \%$ received analgesics while in the ED (Bazarian et al., 2005). Almost 38\% of the ED population was discharged from the ED without recommendations for follow-up (Bazarian et al., 2005). State specific studies again focused on different categories, thus are difficult to compare. In an Ohio study, the odds of requiring a ventilator $(\mathrm{OR}=3.66)$ and being admitted to the ICU $(\mathrm{OR}=2.51)$ were significantly higher for a TBI roadway injury when compared to non-TBI roadway injury (Rochette et al., 2009). In Michigan, more than 4/5 of study subjects received a CT scan while MRI and electroencephalography were used less frequently (Vangel et al., 2005). In Michigan, the most frequent prescriptions filled were anticonvulsant/mood stabilizers (Vangel et al., 2005), however, nationally the most frequently used medicines were analgesics and anxiolytics as well as anticonvulsants in more severe injuries (McGarry et al., 2002).

\subsection{International Health Services Utilization Associated with TBI}

Few studies were found in this review addressing utilization outside the United States. A study of TBI rehabilitation in Italy found that the mean LOS was 87.31 , and $40.4 \%$ of patients had access to rehabilitation facilities after a month (Zampolini et al., 2011). A study of CT use and TBI in some European countries found that CT use in Spain was much lower than Sweden and Germany with only 6\% of patients receiving a CT (Berg, 2004).

\subsection{Disparities in Cost and Utilization Associated with TBI in the United States}

Disparities in health services cost and utilization have been found in the US based on race. Non-White race and lack of insurance were found to be associated with lower likelihood of placement for rehabilitation post-discharge (Heffernan et al., 2011). In South Carolina, uninsured Black females had a lower likelihood of hospitalization (Selassie et al., 2004). A national study of the ED population diagnosed with mild TBI found that Hispanics were more likely to receive a nasogastric tube, while non-Whites were more likely to receive care by a resident and less likely to be sent back to a referring physician after discharge (Bazarian et al., 2003). American Indians and Alaskan Natives (AI/AN) had the highest age adjusted rates of hospitalization for TBI relative to other race/ethnicities (Rutland-Brown et al., 2005)

In one study, private insurance was associated with a shorter length of stay (Heffernan et al., 2011). However, in another study insured patients had a longer length of stay in the intensive care unit (ICU), and lower mortality (Alban et al., 2010). Additionally, in a national study mean and median acute care charges were only slightly higher for males compared with females, however mean and median charges were highest for the western region of the US and for persons covered by Medicaid and those treated in urban teaching hospitals (Schootman et al., 2003).

In a study of unmet needs of individuals with TBI, the most prevalent unmet needs were for memory (50.5\%), job skills (46.3\%), and increasing income (50.5\%) (Heinemann et al., 2002). Black, younger and single individuals as well as those dependent in one or more daily activities and with more recent injuries had greater unmet needs (Heinemann et al., 2002). A review of TBI Medicaid Waivers in six states showed that the ability to obtain a waiver was associated with the social-medical-political climate, ability to strengthen access and reduce barriers, and expenditure of resources (Spearman et al., 2001).

\subsection{International Disparities in Cost and Utilization Associated With TBI}

Among 79 patients with moderate/severe TBI in Netherlands, those with a high locus of control were more likely to visit medical specialists and use supportive care than those with lower levels of internal locus of control. (Willemse-van, 2009). In Australia, rural TBI patients were found to be more likely treated in a non-inpatient setting than urban TBI patients, though this did not appear to significantly impact functional outcomes (O'Callaghan et al., 2009).. Finally, terror victims with TBI were found to have higher rates of brain surgery but no difference in length of stay relative to non-terror victims in Israel (Schwartz et al., 2008).

\subsection{Conclusions}

We reviewed a decade of literature regarding the utilization and cost of health services for TBI in civilian and military adults in the US as well as other countries. We found that cost estimates vary depending on the study population, TBI severity and presence of other mental health co-morbidities. We also found there was evidence of significant racial/ethnic disparities in utilization. However, there is need for further research on cost of TBI over time and better understanding of racial/ethnic, geographic and socioeconomic variations in cost and utilization among individuals with TBI in both civilian and military/Veteran populations in the US and worldwide.

Our study has a number of limitations. We only searched literature since the year 2000 and included studies only published in the English language. We also only reviewed published studies, which may reflect publication bias, 
as some analyses are not published.

We can conclude, however, that the cost and utilization of TBI is an important area of research for the next 5 years, especially considering the growing recognition of the impact of mental health on health costs and outcomes. A potential concern, which has been addressed only marginally in the literature, is racial/ethnic, geographic, and socio-economic disparities in utilization of health services for TBI and its associated co-morbid conditions. There is also a need to control for severity and follow patients over time to truly compare costs and utilization. Future research should investigate the change in cost during the first year vs. over the lifetime, and costs for those who receive mental health services vs. those who do not.

\section{Acknowledgments}

This study was supported by Grant K24DK093699-01 from The National Institute of Diabetes and Digestive and Kidney Disease (PI: Leonard Egede).

\section{References}

Alban, R. F., Berry, C. et al. (2010). Does Health Care Insurance Affect Outcomes After Traumatic Brain Injury? Analysis of the National Trauma Databank. The American Surgeon, 76(10), 1108-1111.

Bazarian, J. J., McClung, J., Cheng, Y. T., Flesher, W., \& Schneider, S. M. (2005). Emergency department management of mild traumatic brain injury in the usa. Emerg Med J., 22(7), 473-477. http://dx.doi.org/10.1136/emj.2004.019273

Bazarian, J. J., Pope, C., et al. (2003). Ethnic and racial disparities in emergency department care for mild $\begin{array}{lllll}\text { traumatic brain injury. Acad Emerg } & \text { Med. 10(11), }\end{array}$ http://dx.doi.org/10.1111/j.1553-2712.2003.tb00605.x

Berg, J. (2004). Economic evidence in trauma: A review. Eur J Health Econ, Suppl 1, S84-91. http://dx.doi.org/10.1007/s10198-005-0293-2

Borg, J., Holm, L. et al., (2004). Non-Surgical Intervention And Cost For Mild Traumatic Brain Injury: Results Of The WHO Collaborating Centre Task Force On Mild Traumatic Brain Injury. J Rehabil Med., Suppl 43, 76-83. http://dx.doi.org/10.1080/16501960410023840

Coronado, V. G., Xu, L., Basavaraju, S. V. et al., (2011) Surveillance for traumatic brain injury-related deaths-United States, 1997-2007. MMWR Surveill Summ. 60(5), 1-32.

Davis, K., Joshi, A., Tortella, B. J., \& Candrilli, S. D. (2007). The direct economic burden of blunt and penetrating trauma in a managed care population. $J$ Trauma 62(3):622-629. http://dx.doi.org/10.1097/TA.0b013e318031afe3

Defense and Veterans Brain Injury Center. (2015). Retrieved from http://www.dvbic.org/dod-worldwide-numbers-tbi.

Egede, L. E., Dismuke, C. E., \& Echols, C. (2012) Racial/Ethnic Disparities in Mortality Risk among Veterans with Traumatic Brain Injury. American Journal of Public Health. 102 Suppl 2, S266-S271. http://dx.doi.org/10.2105/AJPH.2011.300176

Faul, M., Likang, X. et al., (2010) Traumatic Brain Injury in the United States: Emergency Department Visits, Hospitalizations and Deaths, 2002-2006. Atlanta, Georgia: Centers for Disease Control and Prevention, National Center for Injury Prevention and Control. National Estimates of ED and hospital utilization

Hefferman, D. S., Vera, R. M. et al., (2011) Impact of socioethnic factors on outcomes following traumatic brain injury. J Trauma., 70(3), 527-534. http://dx.doi.org/10.1097/TA.0b013e31820d0ed7

Heinemann, A., Sokol, K. et al., (2002) Measuring unmet needs and services among persons with traumatic brain injury. Arch Phys Med Rehabil, 83(8), 1052-1059. http://dx.doi.org/10.1053/apmr.2002.34283

Hodgkinson, A., Veerabangsa, A. et al., (2000). Service utilization following traumatic brain injury. $J$ Head Trauma Rehabil, 15(6), 1208-1226. http://dx.doi.org/10.1097/00001199-200012000-00003

Holloway, R. G., \& Quill, T. E. (2010) Treatment Decisions after Brain Injury-Tensions among Quality, Preference and Cost. NEJM May, 13, 1757-1759.

Hu, J., Ugiliweneza, B. et al., (2013) Trend and Geographic Analysis for Traumatic Brain Injury Mortality and Cost Based on MarketScan Database. $J$ Neurotrauma, 30(20), 1755-1761. http://dx.doi.org/10.1089/neu.2013.2857

Kayani, N., Homan, S. et al., (2009) Health and economic burden of traumatic brain injury: Missouri, 2001-2005. 
Public Health Rep, 124(4), 551-560.

Kreutzer, J., Kolakowsky-Hayner, S., et al., (2001). Charges and lengths of stay for acute and inpatient rehabilitation treatment of traumatic brain injury 1990-1996. Brain Inj., 15(9):763-764. http://dx.doi.org/10.1080/02699050010025786

Leibson, C. L., Brown, A. W. et al., (2010). Medical Care Costs Associated with Traumatic Brain Injury over the Full Spectrum of Disease: A Controlled Population Study. Journal of Neurotrauma, 29, 1-12.

Marwitz J, Cifu D et al., (2001) A multi-center analysis of rehospitalizations five years after brain injury. $J$ Head Trauma Rehabil, 16(4), 307-317. http://dx.doi.org/10.1097/00001199-200108000-00002

McGarry, L., Thompson, D. et al., (2002). Outcomes and costs of acute treatment of traumatic brain injury. $J$ Trauma, 53(6):1152-1159. http://dx.doi.org/10.1097/00005373-200212000-00020

Morgan, M., Lockwood, A. et al., (2012) Pharmacotherapy Regimens Among Patients with Posttraumatic Stress Disorder and Mild Traumatic Brain Injury. Psychiatric Services, 63(2), 182-185. http://dx.doi.org/10.1176/appi.ps.201000531

Morris, S., Ridley, S. et al., (2008) Determinants of hospital costs associated with traumatic brain injury in England and Wales. Anaesthesia, 63(5), 499-508. http://dx.doi.org/10.1111/j.1365-2044.2007.05432.x

O'Callaghan, A., McAllister, L., \& Wilson, L. (2009) Sixteen years on: Has quality of care for rural and non-compensable traumatic brain injury clients improved? Aust J. Rural health, 17, 119-123. http://dx.doi.org/10.1111/j.1440-1584.2009.01054.x

Olesen, J., Gustavsson, A. et al., (2012). The economic cost of brain disorders in Europe. European Journal of Neurology, 19,155-162. http://dx.doi.org/10.1111/j.1468-1331.2011.03590.x

Philips, V., Greenspan, A. et al., (2004) Severity of injury and service utilization following traumatic brain injury: the first 3 months. $J$ Head Trauma Rehabil, 19(3), 217-225. http://dx.doi.org/10.1097/00001199-200405000-00003

Rochette, L., Conner, K., \& Smith, G. (2009). The contribution of traumatic brain injury to the medical and economic outcomes of motor vehicle-related injuries in Ohio. J Safety Res, 40(5), 353-358. http://dx.doi.org/10.1016/j.jsr.2009.08.003

Rockhill, C. M., Jaffe, K. et al., (2012). Health Care Costs Associated with Traumatic Brain Injury and

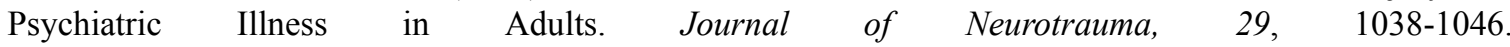
http://dx.doi.org/10.1089/neu.2010.1562

Rutland-Brown, W., Wallace, L. et al., (2005). Traumatic brain injury hospitalizations among American Indians/Alaska Natives. $J$ Head Trauma Rehabil, 20(3), 205-214. http://dx.doi.org/10.1097/00001199-200505000-00004

Schatz, P., Hughes, L., \& Chute, D. (2001) Underutilization of neuropsychology in traumatic brain injury rehabilitation: is managed care to blame? NeuroRehabiliation, 16(4), 281-287.

Schootman, M., Buchman, T., \& Lewis, L. (2003). National estimates of hospitalization charges for the acute

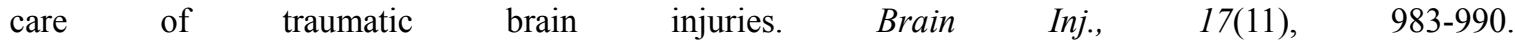
http://dx.doi.org/10.1080/0269905031000110427

Schwartz, I., Tsenter, J. et al., (2007). Rehabilitation Outcomes of Terror Victims with Multiple Traumas. Arch Phys Med Rehabil, 88, 440-448. http://dx.doi.org/10.1016/j.apmr.2007.01.001

Selassie, A. W., Pickelsimer, E. E. et al., (2004). The effect of insurance status, race, and gender on ED disposition of person with traumatic brain injury. Am J Emerg Med., 22(6), 465-473. http://dx.doi.org/10.1016/j.ajem.2004.07.024

Spearman, R., Stamm, B., et al., (2001). The use of Medicaid waivers and their impact on services. $J$ Head Trauma Rehabil, 16(1), 47-60. http://dx.doi.org/10.1097/00001199-200102000-00007

Taylor, B. C., Hagel, E. M. et al., (2012) Prevalence and Costs of Co-occurring Traumatic Brain Injury With and Without Psychiatric Disturbance and Pain Among Afghanistan and Iraq War Veteran VA Users. Medical Care, 50(4), 342-346. http://dx.doi.org/10.1097/MLR.0b013e318245a558

Thompson, H. J., Weir, S. et al., (2012). Utilization and Costs of Health Care after Geriatric Traumatic Brain Injury. Journal of Neurotrauma, 29, 1-8. http://dx.doi.org/10.1089/neu.2011.2284

Thompson, K., Antony, A., \& Holtzman, A. (2001). The costs of traumatic brain injury. NC Med J., 62(6), 
376-379.

Vangel, S., Rapport, L. et al., (2005). Long-term medical care utilization and costs among traumatic brain injury $\begin{array}{llllll}\text { survivors. } & A m & J & \text { Phys } & \text { Med }\end{array}$ http://dx.doi.org/10.1097/01.PHM.0000154896.55045.E7

Wei, W., Sambamoorthi, U. et al., (2005) Mental illness, traumatic brain injury, and Medicaid expenditures. Arch Phys Med Rehabil, 86(5), 905-911. http://dx.doi.org/10.1016/j.apmr.2004.09.026

Willemse-van, Son, A., Ribbers, G., et al., (2009). Is there equity in long-term healthcare utilization after traumatic brain injury? J Rehabil Med, 41(1), 59-65. http://dx.doi.org/10.2340/16501977-0294

Yuan, Q., Liu, H., et al., (2012). Characteristics of acute treatment costs of traumatic brain injury in Eastern China-a mulit-centre prospective observational study. Injury Int $J$ Care, 43(12), 2094-2099. http://dx.doi.org/10.1016/j.injury.2012.03.028

Zampolini, M., Zaccaria, B., et al., (2011) Rehabilitation of traumatic brain injury in Italy: a multi-center study. Brain Inj, 26(1), 27-35. http://dx.doi.org/10.3109/02699052.2011.635358

\section{Copyrights}

Copyright for this article is retained by the author(s), with first publication rights granted to the journal.

This is an open-access article distributed under the terms and conditions of the Creative Commons Attribution license (http://creativecommons.org/licenses/by/3.0/). 